\title{
Corrected Intraocular Pressure Variability with Central Corneal Thickness Measurement
}

This article was published in the following Dove Press journal: Clinical Ophthalmology

Mohamed Attia Ali Ahmed (D)
Ahmed Shawkat Abdelhalim (D)

Ophthalmology Department, Faculty of Medicine, Minia University, Minia, Egypt
Purpose: To evaluate variability in measured intraocular pressure (IOP) values when correlated with central corneal thickness measurements obtained by both ultrasonic and optical tools.

Patients and Methods: We included 46 eyes of 46 healthy subjects (age range 35-76 years). Exclusion criteria for the current study were patients with confirmed diagnosis of glaucoma, glaucoma suspect patients and those having corneal opacities, scars or prior cornea-based laser vision correction. Central corneal thickness (CCT) was measured using two methods: ultrasonically (CCT1) by pachymeter and optically (CCT2) using anteriorsegment optical coherence tomography (AS-OCT). The IOP was measured in all subjects using Goldmann applanation tonometry (GAT).

Results: No significant difference was detected comparing intraocular pressure values and CCT-corrected intraocular pressure (IOPcc1 and IOPcc2) $(P=0.47$ and $P=0.06$, respectively) among the study participants. A significant negative correlation was found between corneal thickness-corrected IOP values and the measured central corneal thickness by both optical and ultrasonic tools $(P=0.004$ and $P=0.001$, respectively).

Conclusion: Intraocular pressure appears to be dependent and positively correlated with CCT changes. However, this does not appear to depend largely on methods used for measuring the CCT in the current study. Corrected intraocular pressure is negatively correlated to both ultrasonically and optically measured central corneal thickness.

Keywords: central corneal thickness, pachymeter, intraocular pressure, corneal thicknesscorrected intraocular pressure, Goldmann applanation tonometry, anterior-segment optical coherence tomography

\section{Introduction}

Pachymetry defined as measuring the corneal thickness has many diagnostic applications in the field of ophthalmology as it is highly correlated to improve the validity of measured intraocular pressure values using standard applanation tonometry. Additionally, in the field of cornea-based refractive surgery, accurate assessment of central corneal thickness has been of paramount importance to assess risk for iatrogenic ectasia. It was suggested that a correction of $1 \mathrm{mmHg}$ for every 25 $\mu \mathrm{m}$ deviation from the CCT of $550 \mu \mathrm{m}$ should be considered. ${ }^{1}$

Ultrasound pachymetry has been considered a gold-standard method when measuring CCT. Nevertheless, it is still associated with some limitations and drawbacks, being operator-dependent and an invasive contact method that motivated scientists to introduce non-contact objective measuring tools. ${ }^{2}$

Central corneal thickness is considered a confounding factor that could affect applanation-measured IOP measurement accuracy. ${ }^{3,4}$
Correspondence: Mohamed Attia Ali Ahmed

Email mohamedattia27@gmail.com
Clinical Ophthalmology 2020:14 450I-4506

4501 
As the cornea gets thicker a greater force is required to applanate, and the reverse is true for thinner corneas. A thin cornea was defined as a risk factor for developing glaucomatous pathology ${ }^{5}$ which is still debatable if it is a sole-effect of corneal thickness or due to its influence on measured IOP values.

The Goldmann applanation tonometer (GAT) has been widely accepted as a reference tool for studying the effect of CCT on IOP measurement values in most previously published studies. Meanwhile, increasing evidence found that other types of tonometers being used in ophthalmic practice share the same issue. ${ }^{6-8}$ To explain the applanation theory, Orssengo and Pye have proposed the thin shell theory which proposed that an applanation force required for a given measured IOP is affected by the multifactorial relationship between corneal rigidity, radius of curvature and thickness. As the applanation area gets smaller, the difference between the applanation pressure and measured IOP gets closer, which is explained by the reduced corneal resistance for the smaller area of contact together with the reduced surface tension effect exerted by the precorneal tear film. ${ }^{9}$

The GAT measurement methodology is primarily based on Imbert-Fick law ${ }^{3,10}$ assuming that human cornea has an infinitely dry thin surface that acts as a "membrane" when the applanating force would be equal to the measured IOP. In ophthalmic practice, the corneal thickness together with the tear film surface tension present a resistance force that counteracts the applanation force which renders the thin membrane theory to be imperfectly correct. The previously mentioned forces neutralize and cancel each other out with a standard GAT applanation diameter of $3.06 \mathrm{~mm}$ when CCT equals $520 \mu \mathrm{m}$, which provides a "reference" value in case the applanating pressure equals the measured IOP. ${ }^{3}$

The Goldmann applanation tonometer has been recognized as a gold-standard method for measuring IOP since it was developed in $1950 .{ }^{11}$ GAT design assumes a central corneal thickness value equals $520 \mu \mathrm{m}$, hence the net measured IOP would be affected if CCT is different from this standard value. ${ }^{12}$ Other studies in the literature reported other factors related to corneal biomechanical parameters also could affect IOP measurements. ${ }^{13-16}$

A thinner CCT has been reported to represent a significant risk in patients diagnosed with primary openangle glaucoma; moreover, patients having thinner CCT were found to have more advanced pathology and a severe glaucomatous defect. ${ }^{5,17}$ Ultrasound pachymetry has been a universally accepted tool for measuring CCT, being highly reproducible and consistent. ${ }^{18}$ On the other hand, Doughty and Zaman found that ultrasonic pachymetric measurements may overestimate the measured corneal thickness compared to that measured optically. ${ }^{19}$ Both Scheimpflug camera-based imaging and spectral-domain optical coherence tomography (SD-OCT) proved to be highly precise, but the SD-OCT showed higher repeatability in comparison. ${ }^{20}$ Our current study evaluated corrected-IOP values' variability among an otherwise healthy population, if any, relating to CCT measured using two different methods.

\section{Patients and Methods Study Design}

Observational case-series of inter-device comparative study.

\section{Study Population}

Forty-six eyes of 46 age and gender-matched healthy subjects were studied. GAT-IOP was measured using Goldmann applanation tonometry (GAT: Haag-Streit AG, Bern, Switzerland) routinely in the initial ophthalmic examination. In all subjects, CCT was measured in the same eye using 2 different methods, namely ultrasonic and optical machines, then values were corrected using the Ehlers formula to get the corrected-IOP values which were compared and correlated. All subjects had at least 2 previous records for IOP and CCT to make sure that values are consistent and reliable enough to include. Included subjects were healthy individuals of both genders aged 48.37 \pm 10.8 years. Glaucoma or glaucoma suspect patients, those having corneal opacities or scars making tonometric and corneal thickness measurements unreliable and inaccurate, having significant refractive errors particularly the axial ametropia that could alter corneal biomechanical properties and prior cornea-based laser vision correction procedures were excluded from the study. Table 1 shows the demographic data distribution in the study participants.

\section{Methods}

All studied subjects had comprehensive ophthalmic examination including the anterior segment together with fundus biomicroscopic examination. IOP was measured by GAT followed by measuring the central corneal thickness by 2 methods independently. 
Table I Study Participants' Demographic Data

\begin{tabular}{|l|l|l|}
\hline Parameters & Mean \pm SD & P-value \\
\hline Number of patients (n) & 46 & - \\
Number of eyes $(\mathrm{n})$ & 46 & - \\
Age (Years) & $48.37 \pm 10.8$ & 0.29 \\
Sex (Female \%) & $\mathrm{II}(57.9 \%)$ & 0.34 \\
IOP (mmHg) & $14.21 \pm 2.28$ & 0.83 \\
IOPccl (mmHg) & $14.62 \pm 2.62$ & 0.26 \\
IOPcc2 (mmHg) & $15.29 \pm 2.6 \mathrm{I}$ & 0.16 \\
CCTI $(\mu \mathrm{m})$ & $539.75 \pm 34.9$ & 0.24 \\
CCT2 $(\mu \mathrm{m})$ & $529.72 \pm 32.2$ & 0.29 \\
\hline
\end{tabular}

Abbreviations: $\mathrm{n}$, number; \%, percentage; $\mathrm{mmHg}$, millimeter of mercury; IOPccl, ultrasonic corneal thickness-corrected intraocular pressure; IOPcc2, optical corneal thickness-corrected intraocular pressure; CCTI, ultrasonically measured central corneal thickness; CCT2, optically measured central corneal thickness; $\mu \mathrm{m}$, micrometer.

\section{Ultrasonic Method}

A corneal ultrasonic pachymeter (Pachmate 2; Model DGH 55B, DGH Technology, Inc., PA, USA) was used after the non-contact (optical) method to not disrupt the ocular surface. Preservative-free topical anesthetizing drops (Oxybuprocaine Hydrochloride 0.4\% w/v. Minims, Bausch \& Lomb UK Ltd, Surrey, UK) were used and then the ultrasonic probe positioned to be perpendicular to the corneal center. An average of 4 consecutive measurements was used for subsequent analysis. Corrected intraocular pressure values were calculated assuming a normal CCT of $545 \mu \mathrm{m} .{ }^{19}$ Correctional value calculation was based on the data of Ehlers et al. ${ }^{3,21}$

\section{Optical Method}

Anterior-segment optical coherence tomography (Cirrus; HD-OCT Model-5000, Carl Zeiss Meditec, Germany) was used to manually measure CCT. A high-definition anteriorsegment line scan was manually centered through a mesopic pupil and then the central line was selected to manually measure the CCT using the built-in software measure tool; 3 measures were compared for consistency and reliability of measured values.

\section{Study Groups}

Study participants' CCT and corrected-IOP values were allocated into two groups based on the method of corneal thickness measurement:

\section{CCTI and IOPccI}

With the central corneal thickness measured by the ultrasonic pachymeter.

\section{CCT2 and IOPcc2}

In which measurement was done using the anteriorsegment optical coherence tomography (AS-OCT). Corrected-IOP and GAT-IOP measurement values were compared and correlated to both CCT1 and CCT2.

\section{Statistical Analysis}

Data were collected, tabulated, verified and coded, then statistical analysis was done using Statistical Package of Social Sciences (IBM, SPSS Statistics for Windows, Version 25.0. Armonk, NY: IBM Corp., Chicago, IL, USA). Qualitative data were presented in descriptive statistics as percentage (\%) and number (n), while quantitative data were presented as mean \pm standard deviation. The Kolmogorov-Smirnov test was used as a normality test to differentiate parametric and non-parametric data. The sample size in the current study provided $89 \%$ statistical power at the $5 \%$ level to detect a $1-\mathrm{mmHg}$ difference in IOP, when the standard deviation (SD) of the mean difference was $1 \mathrm{mmHg}$.

The Mann-Whitney $(U)$ test was used to compare independent quantitative data. Meanwhile, chi-square $\left(\chi^{2}\right.$-test) and Fischer's exact tests were used to compare categorical data. Bivariate Spearman correlation analysis was used for association analysis. $P$-value of less than 0.05 was considered to be statistically significant, if $<0.01$ to be highly significant and if $<0.001$ to be very highly significant.

Correlation or association was graded as follows: weak or no association $0.00-0.24$, mild or fair association 0.$25-0.49$, moderate association $0.50-0.74$, and strong association if $\geq 0.75$.

\section{Results}

We have studied 46 eyes of healthy subjects. No significant difference was noted on comparing age or gender of the study participants. Also, the CCT measured values were not significantly different measured by either ultrasonic or optical method $(p=0.20)$.

No statistically significant difference was found comparing GAT-intraocular pressure and corrected-IOP (IOPcc) values in both studied groups ( $p=0.47, p=0.06$ ) respectively. Similarly, no detected significant difference was there comparing corrected-IOP values between both groups $(p=0.20)$.

Intraocular pressure is positively correlated to cornea thickness-corrected pressure (IOPcc); however, correlation was more significant in the group where the CCT was 
measured optically $(\mathrm{r}=0.54, p=0.001)$ than in the group of ultrasonic-CCT measurement ( $\mathrm{r}=0.46, p=0.004)$.

Corrected intraocular pressure (IOPcc) showed a negative correlation to central corneal thickness; however, correlation was more significant in the group where the CCT was measured optically $(\mathrm{r}=0.59, p<0.001)$.

Both CCT measurement values obtained by ultrasound pachymeter and AS-OCT had a strong positive association $(r=0.95, p<0.001)$. Table 2 shows correlations detected between GAT-measured IOP, corrected-IOP, and CCT values among the study participants.

\section{Discussion}

We could find in the current study a significant positive correlation associating GAT-IOP values and the measured central corneal thickness both by optical and ultrasonic devices ( $P=0.01$ and $P=0.03$, respectively). Meanwhile, a significant negative correlation was detected between corneal thickness-corrected IOP values (IOPcc) and the measured central corneal thickness by both optical and ultrasonic devices $(P<0.001)$. No detectable significant difference was there comparing GAT-intraocular pressure (IOP) and both IOPcc1 and IOPcc2 ( $P=0.47$ and $P=0.06$, respectively).

A previous study reported a significantly reduced correlation between the GAT-measured IOP measurements and central corneal thickness after correcting the IOP for the measured CCT values ( $r$-values reduced from 0.15 to -0.02 ). ${ }^{22}$

In a previous study the CCT effect on measured IOP was reported to be less for GAT-measured IOP $\left(\mathrm{R}^{2}=0.034\right.$, $p=0.067)$ than for non-contact tonometry (NCT) $\left(\mathrm{R}^{2}=0.088\right.$, $p=0.003$ ), which is still in agreement with the correlation reported in the optical pachymetry group in the current study. $^{23}$

Table 2 Correlations Between GAT-IOP, Corneal ThicknessCorrected-IOP and CCT Values Among the Study Participants

\begin{tabular}{|l|l|l|l|}
\hline & & CCTI $(\boldsymbol{\mu m})$ & CCT2 $(\boldsymbol{\mu m})$ \\
\hline IOP $(\mathrm{mmHg})$ & r-value & $0.4 I^{+}$ & $0.36^{+}$ \\
& P-value & $0.01^{*}$ & $0.03^{*}$ \\
\hline IOPccI $(\mathrm{mmHg})$ & $\begin{array}{r}\text { r-value } \\
\text { P-value }\end{array}$ & $\begin{array}{l}-0.60^{\pi} \\
<0.00 I^{* *}\end{array}$ & $\begin{array}{l}-0.62^{\pi} \\
<0.00 I^{* *}\end{array}$ \\
\hline IOPcc2 $(\mathrm{mmHg})$ & r-value & $-0.52^{\pi}$ & $-0.60^{\pi}$ \\
& P-value & $0.00 I^{* *}$ & $<0.00 I^{* *}$ \\
\hline
\end{tabular}

Notes: *Significant; **highly significant; ${ }^{+}$mild association; ${ }^{\top}$ moderate association. Abbreviations: IOP, intraocular pressure; $\mathrm{mmHg}$, millimeter of mercury; IOPccl, ultrasonic corneal thickness-corrected intraocular pressure; IOPcc2, optical corneal thickness-corrected intraocular pressure; CCTI, ultrasonically measured central corneal thickness; СCT2, optically measured central corneal thickness.
In a comparative study comparing POAG, NTG and OHT patients to normal controls, the intraocular pressure was positively correlated with central corneal thickness when measured by Goldmann applanation tonometry but not by Pascal dynamic-contour tonometry. In that study, the central corneal thickness was measured only by ultrasonic pachymetry; also, in our current study we did not use Pascal dynamic contour tonometry for measuring the IOP. ${ }^{24}$

We reported a strong positive association between the measured CCT using both optical and ultrasonic tools, which indicated consistency of both methods; however, previous reports found that optically based OCT devices underestimate the $\mathrm{CCT}$ measurement when compared to ultrasonic pachymetric measurements. ${ }^{25,26}$

Limiting the current study are the relatively small size of the studied sample that included only healthy subjects and the uncontrolled non-randomized design. Furthermore, we only included two methods for corneal thickness measurement, ultrasonic and optical methods, and only used Goldmann-applanation tonometer for measuring the IOP. Those limitations are motivating for running prospective longitudinal cohorts studying larger populations to compare healthy controls to patients with pathological conditions that would affect the measured corneal thickness and/or intraocular pressure measuring values. Other practical methods for measuring the corneal thickness and IOP to be included would help better identify standard correlations to correct the measured IOP for the different CCT measurement values.

\section{Conclusions}

The current study concluded that central corneal thickness could affect the GAT-measured IOP values. However, corrected-IOP values did not differ significantly comparing the ultrasonic or optical methods used for CCT measurement. The GAT-measured IOP values seem to be more correlated to those corrected values for the CCT measured optically using the AS-OCT than ultrasonically.

\section{Abbreviations}

IOP, intraocular pressure; IOPcc, corneal thickness-corrected intraocular pressure; GAT, Goldmann applanation tonometer; CCT, central corneal thickness; SD, standard deviation; $\mathrm{n}$, number; \%, percentage; $\mu \mathrm{m}$, micrometer; $\mathrm{mmHg}$, millimeter of mercury.

\section{Data Sharing Statement}

Datasets analyzed in the current study are readily available on request from the corresponding author. 


\section{Ethics Approval and Informed Consent}

The study research protocol was approved by the institutional review board at the Faculty of Medicine Research Ethics Committee (FMREC), Minia University, Egypt. All study procedures were performed in compliance with the ethical standards guided by the institutional research committee together with the Helsinki Declaration (1964) and its later amendments or comparable ethical standards. Informed consent was obtained from all subjects who participated in the current study.

\section{Acknowledgments}

The authors thank subjects who kindly agreed to participate in the current study.

\section{Author Contributions}

All authors made substantial contributions to conception and design, acquisition of data, or analysis and interpretation of data; took part in drafting the article or revising it critically for important intellectual content; agreed to submit to the current journal; gave final approval of the version to be published; and agree to be accountable for all aspects of the work.

\section{Funding}

No funding received for the current study.

\section{Disclosure}

The authors declare that they have no conflicts of interest.

\section{References}

1. Kohlhaas M, Boehm AG, Spoerl E, Pürsten A, Grein HJ, Pillunat LE. Effect of central corneal thickness, corneal curvature, and axial length on applanation tonometry. Arch Ophthalmol. 2006;124(4):471-476. doi:10.1001/archopht.124.4.471

2. Sedaghat MR, Daneshvar R, Kargozar A, Derakhshan A, Daraei M. Comparison of central corneal thickness measurement using ultrasonic pachymetry, rotating Scheimpflug camera, and scanning-slit topography. Am J Ophthalmol. 2010;150(6):780-789. doi:10.1016/j. ajo.2010.06.013

3. Ehlers N, Bramsen T, Sperling S. Applanation tonometry and central corneal thickness. Acta Ophthalmol. 1975;53(1):34-43. doi:10.1111/ j.1755-3768.1975.tb01135.x

4. Whitacre MM, Stein RA, Hassanein K. The effect of corneal thickness on applanation tonometry. Am J Ophthalmol. 1993;115(5):592-596. doi:10.1016/S0002-9394(14)71455-2

5. Gordon MO, Beiser JA, Brandt JD, et al. The ocular hypertension treatment study: baseline factors that predict the onset of primary open-angle glaucoma. Arch Ophthalmol. 2002;120(6):714-720. doi:10.1001/archopht.120.6.714
6. Dohadwala AA, Munger R, Damji KF. Positive correlation between tono-pen intraocular pressure and central corneal thickness. Ophthalmology. 1998;105(10):1849-1854. doi:10.1016/S01616420(98)91029-6

7. Bhan A, Browning AC, Shah S, Hamilton R, Dave D, Dua HS. Effect of corneal thickness on intraocular pressure measurements with the pneumotonometer, goldmann applanation tonometer, and tono-pen. Invest Ophthalmol Vis Sci. 2002;43(5):1389-1392.

8. Ko YC, Liu CJ, Hsu WM. Varying effects of corneal thickness on intraocular pressure measurements with different tonometers. Eye (Lond). 2005;19(3):327-332. doi:10.1038/sj.eye.6701458

9. Orssengo GJ, Pye DC. Determination of the true intraocular pressure and modulus of elasticity of the human cornea in vivo. Bull Math Biol. 1999;61(3):551-572. doi:10.1006/bulm.1999.0102

10. Gloster J, Perkins ES. The validity of the imbert-flick law as applied to applanation tonometry. Exp Eye Res. 1963;44(2):274-283. doi:10.1016/S0014-4835(63)80048-2

11. Stamper RL. A history of intraocular pressure and its measurement. Optom Vis Sci. 2011;88(1):E16-E28. doi:10.1097/ OPX.0b013e318205a4e7

12. Salvetat ML, Zeppieri M, Tosoni C, Brusini P. Repeatability and accuracy of applanation resonance tonometry in healthy subjects and patients with glaucoma. Acta Ophthalmol. 2014;92(1):e66-e73. doi:10.1111/aos.12209

13. Elsheikh A, Alhasso D, Gunvant P, Garway-Heath D. Multiparameter correction equation for goldmann applanation tonometry. Optom Vis Sci. 2011;88(1):E102-e112.

14. Aziz K, Friedman DS. Tonometers - which one should I use? Eye (Lond). 2018;32(5):931-937.

15. Huseynova T, Waring GO, Roberts C, Krueger RR, Tomita M. Corneal biomechanics as a function of intraocular pressure and pachymetry by dynamic infrared signal and scheimpflug imaging analysis in normal eyes. Am J Ophthalmol. 2014;157(4):885-893. doi:10.1016/j.ajo.2013.12.024

16. Sedaghat MR, Momeni-Moghaddam H, Yekta A, et al. Biomechanically-corrected intraocular pressure compared to pressure measured with commonly used tonometers in normal subjects. Clin Optom (Auckl). 2019;11:127-133. doi:10.2147/OPTO.S220776

17. Herndon LW, Weizer JS, Stinnett SS. Central corneal thickness as a risk factor for advanced glaucoma damage. Arch Ophthalmol. 2004;122(1):17-21. doi:10.1001/archopht.122.1.17

18. Miglior S, Albe E, Guareschi M, Mandelli G, Gomarasca S, Orzalesi N. Intraobserver and interobserver reproducibility in the evaluation of ultrasonic pachymetry measurements of central corneal thickness. $\mathrm{Br}$ J Ophthalmol. 2004;88(2):174-177. doi:10.1136/bjo.2003.023416

19. Doughty MJ, Zaman ML. Human corneal thickness and its impact on intraocular pressure measures: a review and meta-analysis approach. Surv Ophthalmol. 2000;44(5):367-408. doi:10.1016/S0039-6257(00) 00110-7

20. Huang J, Ding X, Savini G, et al. A comparison between scheimpflug imaging and optical coherence tomography in measuring corneal thickness. Ophthalmology. 2013;120(10):1951-1958. doi:10.1016/j. ophtha.2013.02.022

21. Ehlers N, Hansen FK, Aasved H. Biometric correlations of corneal thickness. Acta Ophthalmol. 1975;53(4):652-659. doi:10.1111/ j.1755-3768.1975.tb01784.x

22. Bao F, Huang Z, Huang J, et al. Clinical evaluation of methods to correct intraocular pressure measurements by the goldmann applanation tonometer, ocular response analyzer, and corvis ST tonometer for the effects of corneal stiffness parameters. J Glaucoma. 2016;25 (6):510-519. doi:10.1097/IJG.0000000000000359

23. Kamel K, Dervan E, Falzon K, O'Brien C. Difference in intraocular pressure measurements between non-contact tonometry and goldmann applanation tonometry and the role of central corneal thickness in affecting glaucoma referrals. Ir J Med Sci. 2019;188(1):321-325. doi:10.1007/s11845-018-1795-0 
24. Katsimpris JM, Theoulakis PE, Vasilopoulos K, Skourtis G, Papadopoulos GE, Petropoulos IK. Correlation between central corneal thickness and intraocular pressure measured by goldmann applanation tonometry or pascal dynamic contour tonometry. Klin Monbl Augenheilkd. 2015;232(4):414-418. doi:10.1055/s-0035-1545792

25. de Sanctis U, Missolungi A, Mutani B, Richiardi L, Grignolo FM. Reproducibility and repeatability of central corneal thickness measurement in keratoconus using the rotating scheimpflug camera and ultrasound pachymetry. Am J Ophthalmol. 2007;144(5):712-718. doi:10.1016/j.ajo.2007.07.021
26. Fukuda S, Kawana K, Yasuno Y, Oshika T. Anterior ocular biometry using 3-dimensional optical coherence tomography. Ophthalmology. 2009;116(5):882-889. doi:10.1016/j.ophtha.2008.12.022

\section{Publish your work in this journal}

Clinical Ophthalmology is an international, peer-reviewed journal covering all subspecialties within ophthalmology. Key topics include: Optometry; Visual science; Pharmacology and drug therapy in eye diseases; Basic Sciences; Primary and Secondary eye care; Patient Safety and Quality of Care Improvements. This journal is indexed on PubMed

Submit your manuscript here: https://www.dovepress.com/clinical-ophthalmology-journal
Central and CAS, and is the official journal of The Society of Clinical Ophthalmology (SCO). The manuscript management system is completely online and includes a very quick and fair peer-review system, which is all easy to use. Visit http://www.dovepress.com/ testimonials.php to read real quotes from published authors. 